\title{
Aprendizagens e desaprendizagens sobre direitos sexuais e reprodutivos perante as experiências de saúde das mulheres negras rurais maranhenses ${ }^{1}$
}

\author{
Aprendizaje y desaprendizaje sobre derechos sexuales y reproductivos \\ ante las experiencias de salud de las mujeres negras rurales maranhenses
Learning and unlearning about sexual and reproductive rights in relation to the health experiences of black rural women in Maranhão

Rosângela de Sousa Veras ${ }^{2}$

\begin{abstract}
Resumo
O trabalho apresenta as questões preliminares do estudo sobre saúde sexual e reprodutiva de mulheres negras de comunidades rurais do interior maranhense. Para elas a única política pública de saúde disponível é o Programa Saúde da Família. Quando elas precisam fazer um pré-natal têm que se descolar até a unidade básica de atenção primária, localizada na sede do município, ou mais de $20 \mathrm{~km}$ até o Hospital Geral; caso elas precisem de um parto na rede hospitalar somente encontrarão maternidade nos municípios vizinhos, distantes mais de $30 \mathrm{~km}$. Com estes casos, este artigo quer dar ênfase a outras vivências e práticas de saúde sexual e reprodutiva ainda não contempladas por política públicas universais. Aponta críticas à pretensão universalista dos direitos sexuais e reprodutivos conquistados pelo movimento feminista nas conferências da ONU, na cidade do Cairo em $1994 \mathrm{e}$ em Pequim no ano de 1995. A luta por estes direitos tem sido marcada por reivindicações do livre exercício do corpo, principalmente por mulheres de classes médias. Fato que desperta indagações se todas as mulheres têm a percepção ou a reivindicação do seu corpo como uma propriedade individual? E quais forças sociais bloqueiam o avanço desses direitos a todas as mulheres? Os direitos sexuais e reprodutivos são entendidos como teóricos e utópicos visto que são idealizados como universais sem levar em conta as diferenças e contradições socioculturais. Falar de saúde sexual e reprodutiva de mulheres sem marcar suas pluralidades e sua as fronteiras das desigualdades, faz com que somente uma parte delas seja atendida. Portanto, este estudo reflete criticamente sobre o lugar do outro e a interação de suas múltiplas opressões. Para tanto, se apoia nas teorias interseccionais e nos estudos descoloniais.
\end{abstract}

Palavras-Chave: direitos reprodutivos; estudos descoloniais; interseccionalidade; mulheres negras.

\section{Resumen}

El trabajo aborda las cuestiones preliminares del estudio sobre salud sexual y reproductiva de mujeres negras de comunidades rurales del interior maranhense. Para ellas la única política pública de salud disponible es el Programa Salud de la Familia. Cuando ellas necesitan hacer un prenatal tienen que desprenderse hasta la unidad básica de atención primaria, ubicada en la sede del municipio, o más de $20 \mathrm{~km}$ hasta el Hospital General; en caso de que necesiten un parto en la red hospitalaria sólo encontrarán maternidad en los municipios vecinos, distantes más de $30 \mathrm{~km}$. Con estos casos, este artículo quiere dar énfasis a otras vivencias y prácticas de salud sexual y reproductiva aún no contempladas por derechos universales. Señala críticas a la pretensión universalista de los derechos sexuales y reproductivos conquistados por el movimiento feminista en las conferencias de la ONU, en la ciudad de El Cairo en 1994 y en Pekín en el año 1995. La lucha por estos derechos ha sido marcada por reivindicaciones

\footnotetext{
${ }^{1}$ Artigo apresentado no Simpósio Temático "Fronteiras Culturais em Contextos Epistêmicos Descoloniais II", durante o II Seminário Latino-Americano de Estudos em Cultura - SEMLACult em Foz do Iguaçu/PR, Brasil, 2018.

${ }^{2}$ Mestre em Ciências Sociais; Doutoranda em Ciências Sociais do Programa de Pós-Graduação em Ciências Sociais da Faculdade de Ciências e Letras de Araraquara da Universidade Estadual Paulista - UNESP. Professora de Sociologia do Instituto Federal do Maranhão (IFMA); São Luís, Maranhão, Brasil; rosangelaveras @ifma.edu.br
} 
del libre ejercicio del cuerpo, principalmente por mujeres de clases medias. ¿Hecho que despierta indagaciones si todas las mujeres tienen la percepción o la reivindicación de su cuerpo como una propiedad individual? ¿Y qué fuerzas sociales bloquean el avance de los derechos sexuales y reproductivos a todas las mujeres? Los derechos sexuales y reproductivos son entendidos como teóricos y utópicos, ya que son idealizados como universales sin tener en cuenta las diferencias y contradicciones socioculturales. Hablar de salud sexual y reproductiva de mujeres sin marcar sus pluralidades y su las fronteras de las desigualdades, hace que sólo una parte de ellas sea atendida. Por lo tanto, este estudio refleja críticamente sobre el lugar del otro y la interacción de sus múltiples opresiones. Para ello, se apoya en las teorías interseccionales y en los estudios descoloniales.

Palabras claves: derechos deproductivos; estudios decolonias; interseccionalidad; mujeres negras.

\begin{abstract}
The paper presents the preliminary questions of the study on sexual and reproductive health of black women from rural communities in the interior of Maranhão. For them, the only available public health policy is the Family Health Program. When you follow up on pregnancy, find out to the primary care unit, it is located at the county seat, or more than $20 \mathrm{~km}$ to the General Hospital; if they need a birth in the hospital network will only find maternity in the neighboring municipalities, distant more than $30 \mathrm{~km}$. With these cases, the article wants to emphasize other experiences and practices of sexual and reproductive health not yet contemplated by universal public policy. It points to criticism of the universalist claim to sexual and reproductive rights won by the women's movement at United Nations Organization conferences in Cairo in 1994 and in Beijing in 1995. The struggle for these rights has been marked by demands for the free exercise of the body, especially by middle-class women. A fact that raises questions if all women have the perception or claim of their body as an individual property? Sexual and reproductive rights are understood as theoretical and utopian as they are conceived as universal without regard to social and cultural differences and contradictions. To speak of sexual and reproductive health of women without marking their pluralities and their borders of inequalities, causes only a part of them to be attended to. Therefore, this study reflects critically on the place of the other and the interaction of its multiple oppressions. This is based on intersectional theories and descolonial studies.
\end{abstract}

Keywords: reproductive dights; descolonial studies; intersectionality; black women.

\title{
1. Introdução
}

O Governo Federal reconhece que no Brasil rural vivem mais de 14 milhões de mulheres, representando $48 \%$ da população destas áreas, no campo $24,8 \%$ das mulheres são responsáveis por suas famílias (Censo, 2010). A escolaridade dessas mulheres é baixa, 52,3\% são analfabetas ou têm apenas 3 anos de estudos. (BRASIL, 2015).

No estado do Maranhão, boa parte dessas mulheres são negras e trabalhadoras rurais, residem em comunidades ou povoados do interior, algumas pertencem a comunidades autodenominadas remanescentes de quilombos e também são beneficiadas por projetos governamentais de assentamento rural, aplicados durante a década de 1990.

A sua cultura é de subsistência, elas produzem o alimento e garantem a subsistência da família a partir de trabalhos como, o roçado, a extração do coco babaçu, a produção do azeite e do mesocarpo deste coco, a queima da sua casca para fazer o carvão, do artesanato da palha da palmeira do babaçu, de programas sociais do Governo Federal e de projetos de organizações não governamentais. Além do trabalho na produção agrícola ainda são mães e donas de casa. (LIMA, 2015). 
Para os povoados maranhenses a política pública de saúde mais acessível é o Programa Saúde da Família, que disponibiliza, em média, um agente de saúde para atender a 130 famílias. Como elas têm dificuldade de se deslocar para obter acesso à saúde hospitalar no meio urbano, é muito comum que essas mulheres utilizem estratégias culturais para auxiliar na manutenção da saúde, como o uso de remédios caseiros, benzedeiras, rezadeiras. Já as parteiras estão cada vez mais raras, muitas já faleceram.

As mulheres das gerações mais novas apontam dificuldades de acesso à assistência da saúde da mulher, no que tange ao exame ginecológico papanicolau e ao pré-natal. Quando elas precisam fazer um pré-natal têm que se descolar, por volta de 10 a $20 \mathrm{~km}$, até a unidade básica de atenção primária, na sede do município; caso elas precisem de um parto na rede hospitalar somente encontraram maternidade nos municípios vizinhos que dispõem de médico obstetra, alguns distantes mais de $30 \mathrm{~km}$.

Esse quadro é resultado da pouca abrangência da política Nacional de Atenção Integral à Saúde da Mulher (PNAISM) implementada pelo estado brasileiro, no ano de 2004, fruto do compromisso assumido na ocasião das conferências da Organização das Nações Unidas (ONU) realizadas em Viena no ano de 1993 (II Conferência Internacional de Direitos Humanos), no Cairo em 1994 (Conferência Internacional sobre População e DesenvolvimentoCIPD) e Pequim em 1995 (IV Conferência Mundial sobre a Mulher).

Durante a CIPD, a saúde reprodutiva foi definida como,

um estado de completo de bem-estar físico, mental e social em todas as matérias concernentes ao sistema reprodutivo, suas funções e processos, e não apenas mera ausência de doença ou enfermidade. A saúde reprodutiva implica, por conseguinte, que a pessoa possa ter uma vida sexual segura e satisfatória, tendo a capacidade de reproduzir e a liberdade de decidir sobre quando e quantas vezes deve fazê-lo (CIPD, 1994).

Esta definição tem uma conotação baseada nas garantias de liberdades individuais, contudo, a luta por esta condição básica de saúde sexual e reprodutiva tem a cada dia reivindicações pela ampliação da dimensão social desses direitos e da resposta de políticas públicas que os garanta.

É neste sentido que este estudo privilegia o caso dessas mulheres negras de comunidades rurais quilombolas, pois ao dar ênfase a seus casos específicos apresenta outras vivências e práticas de saúde sexual e reprodutiva ainda não contempladas por direitos e políticas públicas concebidas como universais.

Para isto, é imprescindível considerar a existência de uma teia de relações e tensões que envolvem as condições de saúde sexual e reprodutiva dessas mulheres, sejam: suas relações 
sociais, sua diversidade cultural e a interconexão das desigualdades que as marcam, visto que se trata de mulheres (gênero), negras (etnia) e trabalhadoras rurais (classe).

Dado o fato de que as mulheres brancas e de classe média estiveram à frente da luta pelas liberdades individuais femininas, esta análise tenta justamente superar o risco de apresentar problemas de um determinado grupo de mulheres como problemas universais. Conforme argumenta Scavone, "a crítica ao pretenso universalismo de determinadas categorias analíticas feministas encontrou seu contraponto na afirmação das diferenças e alteridade" (SCAVONE, 2004, p. 35).

Ao mesmo tempo, este estudo considera as singularidades e desigualdades que marcam as mulheres negras rurais, entende que suas particularidades mesmo que localizadas são fruto de uma construção histórico-social maior.

Por este motivo, como lente de análise, este estudo se apoia nos estudos interseccionais, que são ferramentas metodológicas que entendem a classe, a etnia e o gênero como um sistema de opressões interligadas; e, também, nos estudos descoloniais que buscam desessencializar a visão negativa das diferenças, entendidas não como uma condição dada, mas como fruto de uma condição estrutural. São estudos que visam descolonizar saberes e subverter os discursos totalizantes.

\section{Discussões teóricas que orientam a dimensão social da saúde da mulher}

Existem várias teorizações sobre a saúde sexual e reprodutiva das mulheres, há conceitos mais restritos que abordam a questão centrada no aspecto biológico e na anatomia do corpo da fêmea. Diferentemente, este artigo não reduz a mulher a sua condição biológica porque parte do pressuposto de que as representações do corpo e do que é ser mulher é fruto de construções histórico-sociais que variam de cultura para cultura. Portanto, não é possível discutir sobre saúde sexual e reprodutiva sem pontuar que as mulheres não são iguais entre si e que nem todas têm acesso a políticas públicas de saúde, uma vez que são marcadas pela classe social, a etnia, a localização e demais marcadores sociais segundo o contexto em que estão inseridas.

Para dar conta desta complexidade existem várias ferramentas de análise que auxiliam sua compreensão. Uma delas é a categoria gênero que, nas palavras de Scott, "é um elemento constitutivo de relações sociais baseadas nas diferenças percebidas entre os sexos, o gênero é uma forma primeira de significar as relações de poder" (SCOTT, 2014, p.21). 
Os gêneros são construídos na dinâmica das relações sociais perpassadas por antagonismo em que lhes são atribuídos poderes desiguais. Essa ferramenta analítica, também quebra a visão universal do conceito de mulher. A teórica Ângela Davis, em seu livro "Mulheres, raça e classe" ajuda nessa discussão ao desconstruir o mito da fragilidade feminina quando retrata o caso das mulheres negras norte-americana no período escravocrata.

As mulheres negras escravizadas, referidas pela autora, nunca foram tratadas como frágeis e não eram tratas com nenhum privilégio em relação aos homens negros escravizados. Ambos trabalhavam duro na lavoura, sofriam castigos e açoites, elas não eram poupadas do trabalho duro nem durante a gestação e a amamentação. Em ralação aos homens negros, as mulheres negras sofriam uma punição a mais, pois eram estupradas por seus donos. Sob a opressão colonial eram vistas apenas como reprodutoras e até a sua maternidade era negada porque muitos de seus filhos eram vendidos.

Anos se passaram do período da escravidão, contudo as sociedades coloniais não superaram os frutos das suas desigualdades que, autoras como Collins (2018), definem como sistema de opressão que incidem mais sobre uns corpos do que outros.

Mesmo que as sociedades modernas tenham definido um conjunto de direitos que buscam garantir a dignidade da pessoa humana, esses não conseguem ter uma abrangência efetivamente universal.

Para Crenshaw (2002), mesmo que a Declaração Universal dos Direitos Humanos garanta a sua aplicação sem a distinção de classe, etnia, gênero; outrora, os direitos das mulheres e as circunstâncias específicas em que elas sofriam abusos eram entendidos como sendo diferentes da visão clássica de abuso de direitos humanos e, portanto, marginais dentro de um regime de aplicação universal. Já quando mulheres eram detidas, torturadas ou lhes eram negados outros direitos civis e políticos, de forma semelhante ao que acontecia com os homens, tais abusos eram obviamente percebidos como violações. Porém, quando mulheres, sob custódia, eram estupradas, espancadas no âmbito doméstico ou quando alguma tradição lhes negava acesso à tomada de decisões, suas diferenças em relação aos homens tornavam tais abusos periféricos em se tratando das garantias humanas básicas.

Foi a partir da contestação e a reivindicação do movimento de mulheres que houve a incorporação da perspectiva de gênero nas discussões dos Direitos Humanos. O legado da luta do movimento de mulheres se institucionalizou a partir das conferências organizadas pela Organização das Nações Unidas em Viena no ano de 1993, na Conferência da cidade do Cairo em 1994 e na Conferência de Pequim - China em 1995, quando os direitos sexuais e reprodutivos foram entendidos como direitos humanos. 
As interpretações teóricas, conforme Ávila (2003), sobre esses direitos é que os direitos sexuais tratam da igualdade e liberdade no exercício da sexualidade e os direitos reprodutivos dizem respeito à igualdade e à liberdade na esfera da vida reprodutiva.

Segundo Minella (2005), as discussões sobre as garantias da liberdade do indivíduo decidir livremente sobre sua sexualidade e reprodução contribuem com uma definição mais ampla e apurada de saúde sexual e reprodutiva que, transcende um modelo de assistência à saúde centrada no ponto de vista biomédico, para uma definição que adere a liberdade e a dignidade da pessoa humana no campo do comportamento reprodutivo.

Entretanto, a medida que os movimentos sociais avançam na luta por cidadania esses direitos passam a ser reivindicados na sua dimensão social, contribuindo para o entendimento de que a saúde e a reprodução humana também são influenciadas por aspectos sociais e desigualdades estruturais e isto deve ser contemplado ao se tratar de direitos, de cidadania e de políticas públicas.

Conforme a definição da política de saúde da mulher, esses direitos compõem o acesso às políticas públicas de prevenção e à assistência à gravidez na adolescência, ao prénatal, ao parto, ao puerpério, à interrupção voluntária da gravidez, menopausa, prevenção ao câncer de mama e do colo de útero, IST's (Infecções Sexualmente Transmissíveis) e AIDS (Síndrome da Imudeficiência Adquirida), contracepção, dentre outros direitos.

Durante a IV Conferência das Nações Unidas sobre Mulher, em Pequim (1995), definiu-se uma plataforma de ação para que as mulheres pudessem exercer plenamente seus direitos e alcançar seu desenvolvimento integral como pessoas.

O Brasil signatário da ONU, definiu algumas políticas públicas de atenção à saúde da mulher com vistas a contemplar os direitos sexuais e reprodutivos. Em 1984, o Ministério da Saúde elaborou o Programa de Assistência Integral à Saúde da Mulher (PAISM), em 2004, foi definida a Política Nacional de Atenção Integral à Saúde da Mulher (PNAISM) e em 2009 instituiu a Política Nacional de Saúde Integral da População Negras (PNSIPN).

Passados 24 anos da instituição da plataforma de ação e da definição de algumas políticas públicas de saúde das mulheres e da população negra, a garantia desses direitos ainda encontra desafios e entraves na sua efetivação. Um dos maiores desafios a garantia universal é justamente contemplar, a contento, as particularidades culturais e regionais das mulheres brasileiras.

Para Scavone (2004), o conceito de direito e saúde sexual-reprodutiva são teóricos e utópicos. As características reprodutivas (aborto, pré-natal, parto, câncer de mama e de colo do útero, infecções sexualmente transmissíveis e AIDS - Síndrome da Imudeficiência 
Adquirida, gravidez na adolescência, programas de planejamento reprodutivo entre outros aspectos) são abordadas como problemas universais de gênero e não levam em considerações as contradições socioculturais.

A autora argumenta ainda que,

Esta universalidade não é absoluta, ela [deve ser] tratada com base numa abordagem relacional e histórica buscando identificar os aspectos decorrentes de uma situação de dominação e de poder masculino (na relação com o companheiro, com os médicos e com as instituições de saúde) e os aspectos decorrentes de outro pólo de poder no qual as mulheres têm primazia pelo autoconhecimento de seus corpos, no domínio da contracepção, realização ou recusa da maternidade, ambos em tensão na luta política pela transformação das condições de saúde das mulheres (SACVONE, 2004, p. 48).

Esta citação aponta uma crítica a categoria universal "mulher", chama a atenção para pluralidade do ser mulher e da multiplicidade de tensões sociais que elas têm que enfrentar para atingir as liberdades nas esferas sexuais e reprodutivas de suas vidas.

A linguagem liberal dos direitos sexuais e reprodutivos foi formulada, em geral, por mulheres de classes médias para contrapor às concepções conservadoras de subordinação do corpo e da sexualidade das mulheres, tem na sua base a reivindicação do livre exercício do corpo, entendido como uma propriedade individual. Tal proposta feminista desperta para a indagação se todas as mulheres têm a percepção e a reivindicação do corpo como uma propriedade individual?

Isto nos leva a intuir que essa pretensa universalidade entra em contradição diante do caso específico das mulheres negras rurais maranhenses que relatam inúmeras dificuldade de acesso a estes direitos. Se considerarmos conjuntamente suas desigualdades de gênero, étnicas e regionais, essas mulheres podem vivenciar discriminações e outros descumprimentos dos direitos sexuais e reprodutivos de uma maneira diferenciada das mulheres de outra classe e dos homens.

Por isso, é preciso focalizar as várias diferenças sofridas por um determinado grupo em nome de uma maior inclusão de direitos. Dessa forma, o uso da ferramenta analítica interseccionalidade ajuda na discussão das várias formas pelas quais a raça e o gênero podem se entrecruzar.

\section{Conforme Crenshaw,}

Assim como é verdadeiro o fato de que todas as mulheres estão, de algum modo, sujeitas ao peso da discriminação de gênero, também é verdade que outros fatores relacionados a suas identidades sociais, tais como classe, casta, raça, cor, etnia, religião, origem nacional e orientação sexual, são "diferenças que fazem diferença" na forma como vários grupos de mulheres vivenciam a discriminação (CRENSHAW, 2002, P. 173). 
A autora argumenta que a raça/etnia, a classe, o gênero e outros marcadores associados compõem sistemas múltiplos de subordinação que criam desigualdades e colocam em vulnerabilidade grupos específicos de mulheres.

Considerando que o sujeito é constituído mediante experiências que se dão em contextos específicos e com múltiplas relações, é imprescindível considerar que ser mulher, negra e trabalhadora, é reunir em si três marcadores sociais, que são fruto de construções socioculturais definidas tanto nas relações instituídas no grupo como nas relações estruturais da sociedade brasileira.

A dificuldade de se fazer cumprir os direitos sexuais e reprodutivos deve-se à essas estruturas de poder. Portanto, conforme Mouffe (1996), as concepções de liberdades individuais pregadas pelo estado liberal precisam ser desmistifica com o argumento de que a pretensa imparcialidade dos direitos acaba por naturalizar as relações de subordinação e opressão e não é capaz de atender aos grupos subjugados do processo histórico de dominação.

Assim, este artigo constata que somente a institucionalização dos direitos sexuais e reprodutivos, e considera-los como uma ampliação dos direitos humanos, não é garantia de acesso, visto que não são suficientes para dar conta da complexidade das vidas das pessoas que os requerem, principalmente as residentes nos países considerados periféricos ou emergentes onde as políticas públicas e seu acesso ainda são restritos por não abranger a pluralidade e a diversidade das vivências das mulheres.

Quais forças estruturais bloqueiam o avanço desses direitos?

Respostas a esta questão ainda não temos, um passo importante na busca de ampliar a discussão é considerar as experiências de um grupo específico de mulheres e suas condições de saúde sexual e reprodutiva face suas relações sociais permeadas por poderes locais e globais.

Avtar Brah (2006), ajuda nessa argumentação ao dizer que a experiência é o lugar de formação do sujeito e o sujeito é constituído mediante experiências que se dão em contextos de múltiplas relações. Para Brah,

Nosso gênero é constituído e representado de maneira diferente segundo nossa
localização dentro de relações globais de poder. Nossa inserção nessas relações
globais de poder se realiza através de uma miríade de processos econômicos, políticos
e ideológicos. Dentro dessas estruturas de relações sociais não existimos
simplesmente como mulheres, mas como categorias diferenciadas, tais como
"mulheres da classe trabalhadora", "mulheres camponesas" ou "mulheres imigrantes"
[...] Diferença nesse sentido é uma diferença de condições sociais (BRAH, 2006,
p.341). Concordamos com a autora ao considerar que a experiência do ser mulher é particular, mas também que sofre influência de relações globais de poder. Para considerar as 
experiências do sujeito mediante o local de pertencimento, deve-se analisa-las de maneira interseccional e não isoladamente.

É por este motivo que os estudos interseccionais auxiliam no estudo da saúde das mulheres negras rurais, pois procura entender como a intersecção das opressões sofridas colocam grupos em lugares mais vulneráveis que outros. Isto exigem uma nova orientação epistêmica ao evitar a análise essencializada, isto é, as situações de vulnerabilidade devem ser entendidas com um construto histórico e social.

Essa discussão contribui para a questão da ampliação da abrangência dos direitos sexuais e reprodutivos, porque eles têm que compor uma agenda de reparação social que reduza ou supere as desigualdades sociais, pois superar desigualdades é fazer justiça social com vistas a proporcionar políticas focadas a grupos específicos e mais vulneráveis.

\section{Considerações Finais}

Com o exposto, este artigo pretendeu reforçar o pressuposto de que os direitos sexuais e reprodutivos só podem ser considerados garantias da dignidade da pessoa humana se as políticas públicas que os abrigam, além de garantir as liberdades individuais, devem também considerem adequadamente a sua dimensão social e reconheçam as particularidades das múltiplas experiências do ser mulher em meio as fronteiras de sua desigualdade para a sua superação.

\section{Referências}

ÁVILA, Maria Betânia de Melo. Modernidade e cidadania reprodutiva. CFEMEA, Brasília (CF), 1994. p.9-25.

BRAH, Avtar. Diferença, diversidade, diferenciação. Disponível em: 〈http://www.scielo.br/pdf/cpa/n26/30396.pdf〉. Acesso em: 04 de janeiro de 2016.

BRASIL. Secretaria de Políticas para as Mulheres (SPM). "Igualdade de Gênero no Campo, na Floresta e nas Águas". Disponível em: < http://www.spm.gov.br/assuntos/mulheres-docampo-e-da-floresta>. Acesso em 07 de dezembro de 2015.

BRASIL. Ministério do desenvolvimento agrário. Gênero, agricultura familiar e reforma agrária no Mercosul, Brasília, 2006.

COLLINS, Patricia Hill. Se perdeu na tradução? Feminismo negro, interseccionalidade e política emancipatória. Disponível em:

http://revistaseletronicas.fiamfaam.br/index.php/recicofi/article/view/559. Acesso em 28/12/18. 
CRENSHAW, Kimberlé. Documento para o encontro de especialistas em aspectos da discriminação racial relativos ao gênero. Estudos feministas. Ano 10, $1^{\circ}$ semestre, 2002.

LIMA, Maria Deuzamar. O Coletivo de Mulheres Trabalhadoras Rurais do Maranhão: participação política e mudança social da mulher trabalhadora rural. 2015. 40f. Monografia Curso de Pós-Graduação Especialização em Questão Agrária, Agroecologia e Educação, Instituto de Educação Ciência e Tecnologia Campus São Luís Maracanã, São Luís, 2015.

MINELLA, Luzinete Simões. Gênero e Contracepção: uma perspectiva Sociológica. Florianópolis: Ed. da UFSC, 2005.

MOUFFE, Chantal. O Regresso do político. Lisboa: Gradiva, 1996.

SCAVONE, L. Dar e cuidar da vida: feminismo e Ciências Sociais. São Paulo: Editora UNESP, 2004.

SCOTT, Joan. GÊNERO: uma categoria útil para análise histórica. Disponível em: <http://www.observem.com/upload/935db796164ce35091c80e10df659a66.pdf> Acesso em: 04 de agosto de 2014. 